\title{
Negociações desiguais \\ Resistência na relação entre trabalhadores rurais e criadores de gado no Sul do Brasil
}

\author{
Uneven negotiations \\ Resistance in the relationship between ranchers and \\ ranch hands in southern Brazil.
}

Luciano Bornholdt*

\begin{abstract}
Resumo: A partir de um estudo etnográfico realizado em estâncias de criação de gado da Campanha gaúcha, Rio Grande do Sul, Brasil, este artigo discute a relação entre os proprietários das estâncias e os peões que trabalham nas mesmas. Patrões (estancieiros) e peões compartilham certas características em termos de comportamento econômico. Entretanto, as diferenças culturais, assim como suas posições distintas na hierarquia da relação, implicam irremediavelmente em desigualdades cruciais. Enquanto as estratégias de reprodução de posição social de famílias de estancieiros são relativamente variadas, os peões enfrentam elevada dificuldade de ascensão social. Essas desigualdades transparecem em certos elementos dos projetos de resistência dos peões à dominação exercida por seus patrões. É através desses projetos de resistência que este artigo analisará as ambigüidades e dinâmicas dessa relação.
\end{abstract}

Palavras-chave: Dominação/resistência; Valores; Peões gaúchos; Estancieiros; Comportamento econômico

\begin{abstract}
Based on ethnographic fieldwork carried out in cattle ranches of the Campanha gaúcha region, state of Rio Grande do Sul, Brazil, this paper analyses the relationship between ranchers and the ranch hands working for them. Ranchers (in Portuguese patrões or estancieiros) and peões (the ranch hands) share certain characteristics regarding their economic choices and behaviour. Nevertheless, the cultural differences between them, as well as the distinct positions they occupy in the hierarchy of their relationship, imply irrevocably on strong differences. While the reproduction strategies of estancieiro families' social position are varied, peões face the unlikelihood of social ascension. These differences are more visible in certain elements of the peões ' projects of resistance to the domination by their patrões. It is through these projects of resistance that this article will analyse the ambiguities and dynamics of this relationship.

Keywords: Domination/resistance; Values; Peões gauchos; Estancieiros; Economic behaviour

* Doutor em antropologia social pela Universidade de Manchester. Antropólogo e coordenador de projetos na JGP Consultoria e Participações Ltda., especializada em gestão ambiental. $<$ luciano.cb@gmail.com>.
\end{abstract}

\begin{tabular}{|l|l|l|l|l|l|}
\hline Civitas & Porto Alegre & v. 10 & n. 3 & p. 513-526 & set.-dez. 2010 \\
\hline
\end{tabular}




\section{Introdução}

A atual Campanha gaúcha, área de campos no sul do estado do Rio Grande do sul, Brasil, foi uma área de fronteira disputada entre Portugal e a Espanha e, posteriormente, entre o Brasil, Uruguai e Argentina. Nessa fronteira dinâmica e em constante transformação, sujeita apenas parcialmente ao controle dos Estados envolvidos, os caçadores de gado seminômades, que posteriormente seriam conhecidos como gaúchos ${ }^{1}$, foram capazes de sustentar um modo de vida utilizando como principal recurso o gado selvagem descendente dos animais trazidos pelos jesuítas no século XVI. A carne e o couro eram, respectivamente, a base de sua alimentação e de sua cultura material. A riqueza em gado selvagem da região fronteiriça desde cedo atraiu a atenção de espanhóis e portugueses. A princípio, desde aproximadamente 1680, Portugal exportava o couro para a Europa, enquanto a carne era deixada apodrecendo nos campos por falta de mercado e de tecnologia disponível para o seu processamento. No início do século XVIII, a área começou a ser integrada à economia de exportação da colônia e, conseqüentemente, o gado passou a ser mais valorizado (Pesavento, 2002).

No interior do Rio Grande do Sul, próximo à região de fronteira, durante a primeira e a segunda década do século XVIII, estradas começaram a ser delimitadas para o transporte de gado, assim como pastagens de inverno e currais. Portugal começou a distribuir grandes áreas de terra, visando garantir seu controle da região, através de ocupação efetiva da mesma (Kühn, 2004; Pesavento, 2002). O governo imperial continuou provendo grandes áreas de terra a indivíduos, e os gaúchos tiveram sua mobilidade e seu acesso aos recursos cada vez mais reduzidos. Embora contemporaneamente o termo gaúcho tenha sido promovido a ícone de identidade nacional, no caso da Argentina e do Uruguai, ou regional, no caso do estado brasileiro do Rio Grande do Sul, ele já foi usado pejorativamente para se referir a bandidos e desertores, pessoas - normalmente homens - não ligadas ao trabalho pago ou à propriedade da terra. Essa valoração pejorativa do termo estava ligada aos esforços de dominação desprendidos por uma elite regional proprietária de terra, apoiada pelo Estado. De acordo com Slatta (1983), a passagem do gaúcho da autossuficiência para a peonagem dependente foi o resultado dos esforços diligentes de estancieiros e políticos.

1 No contexto deste artigo, utilizo "gaúcho", iniciando em minúscula, para me referir ao peão gaúcho. É verdade que os estancieiros também podem se considerar Gaúchos, assim como Gaúcho é o gentílico do Estado do Rio Grande do Sul, mas essa discussão será apresentada apenas brevemente no presente texto. 
A partir do final do século XVIII, tanto a Campanha gaúcha quanto o norte do Uruguai passaram a ser marcados pela presença das estâncias, grandes ranchos de criação de gado que substituíram os campos abertos. $\mathrm{O}$ erguimento de cercas na Campanha foi parte importante do processo de mudança no regime de propriedade da terra que, associado a mudanças nos direitos sobre o gado selvagem, levou os gaúchos a uma mudança de modo de vida. Eles foram lentamente - embora através de um violento processo de pacificação e do uso de métodos ditatoriais - disciplinados à lógica da estância, como peões, desempenhando trabalho pago e suprindo os exércitos e pelotões dos seus patrões nas inúmeras guerras da região.

Os estancieiros formavam uma elite econômica, política e militar na região da fronteira. Essa elite regional conseguiu estabelecer com os gaúchos, agora peões, uma relação de dominação que é sustentada até o presente, embora com seus termos específicos modificados. Contemporaneamente, o peão gaúcho está presente nesta região, nos três países fronteiriços, e, embora nem sempre trabalhe efetivamente nas estâncias, é comumente pensado em relação àquele universo rural específico.

Processos relativamente mais recentes têm modificado a situação e as opções disponíveis para o gaúcho. Ele enfrenta restrições que o forçam a adaptar seus desejos e esperanças, bem como o resultado de seus projetos, a uma realidade imperfeita. Seu desejo de viver uma vida rural, um estilo de vida identificado como gaúcho, se choca com as mudanças técnicas introduzidas na pecuária, com a urbanização da elite criadora de gado, com mudanças cruciais nos modos de produção agrícola e com mudanças nas relações de clientelismo entre patrão e peão, com as quais ele aprendeu a contar. A soma desses e de outros fatores tem tornado o campo cada vez menos atraente, reforçando o êxodo rural. As elites rurais também estão mudando, tanto como resposta a novos desafios econômicos, quanto para saciar seus novos desejos de bens de consumo e em razão do estilo de vida urbano, agora disponível a elas.

\section{Desafios e respostas}

Embora a criação extensiva de gado tenha, por um longo tempo, ocupado a maior parte da terra na Campanha gaúcha, deslocando os gaúchos e controlando-os como força de trabalho, a chegada relativamente recente de agricultores, na década de 1960, promoveu uma reorganização da estrutura agrária regional. Agricultura intensiva, especialmente o cultivo de arroz, provou ser mais rentável do que a criação de gado na região e, conseqüentemente, tem avançado sobre áreas anteriormente utilizadas como pasto para o gado. O cultivo de arroz possui um ciclo produtivo mais curto do que a criação 
de gado. Além disso, uma proporção considerável dos agricultores chegou capitalizada à região, oriunda de outras áreas agrícolas do estado. Pequenos criadores de gado freqüentemente sucumbem às pressões do capital agrícola e vendem suas terras para serem usadas para o cultivo de arroz, ou alugam as terras temporariamente, mas acabam descapitalizados, não sendo capazes de retomar suas atividades produtivas.

Apesar disso, em geral, os estancieiros conseguiram responder a este e a outros desafios, e obtiveram um relativo sucesso na manutenção de algum poder político e econômico na região. Diversos criadores de gado foram capazes de controlar parte das mudanças na economia local através das velhas formas institucionais, tais como a patronagem com outros grupos sociais e a associação hierarquizada entre estancieiros, estabelecendo parcerias e relacionamentos com agricultores. Enquanto os primeiros tinham a terra, os últimos possuíam o conhecimento e o capital, numa relação que tem se mostrado mutuamente lucrativa. Essa estratégia tem sido importante para manter a pecuária economicamente viável, e pode vir a ser um dos fatores chave na sobrevivência da criação extensiva de gado na região.

Assim como seus patrões, os peões são agentes capazes de responder às mudanças que identificam como ameaças ao seu modo de vida. Ambos, estancieiros e peões são obrigados a fazer escolhas em um mundo de opções limitadas. Os peões são, entretanto, menos capazes de limitar os efeitos dessas mudanças sobre suas próprias vidas, constrangidos que estão pela posição dominada que ocupam em sua relação com a elite proprietária de terra, da qual fazem parte os seus patrões.

Além dos limites impostos pela sua situação de dominados, outro fator que influência as respostas aos desafios está ligado às particularidades e diferenças dos universos culturais de patrões e peões. Seus projetos não surgem de uma razão universal, nem são exclusivamente determinadas pelo contexto. Eles resultam das escolhas individuais dos sujeitos frente a um contexto em mudança, dinamicamente reelaboradas a partir de seus medos e desejos, e informadas por seu repertório cultural.

\section{Valores}

As mudanças na atividade pecuária que reduzem o número de peões empregados, assim como a redução na área total dedicada à criação de gado resultante da expansão da agricultura, reduzem o leque de alternativas a partir do qual os peões podem fazer suas opções de vidas. O êxodo rural é resultante tanto da atração exercida por áreas mais urbanizadas e pelos serviços ali oferecidos, quanto pelo número limitado de opções disponíveis nas áreas 
rurais. A vida de um peão é feita de longas horas de trabalho duro e, muitas vezes, de semanas a fio longe de sua família. Mesmo assim, uma vida a cavalo ainda é muito atraente para eles. Na situação hipotética de poder fazer escolhas não limitadas por restrições práticas, os peões freqüentemente optam por uma vida na área rural, uma vida na campanha. Uma vida que lhes permite fruir da interação com o ambiente específico da campanha, através de suas habilidades com cavalos, gado, laços e facas. Essa vida concreta, entretanto, demanda um alto grau de concessões, de escolhas entre opções imperfeitas, negociadas com seus patrões e exigindo criatividade no desenvolver seus próprios projetos.

Julio nos oferece um bom exemplo das opções que a vida oferece aos peões. Importantes projetos, como aqueles relacionados ao trabalho e ao matrimônio, surgem algumas vezes em seus relatos, contrastando com uma vida imaginária em que há abundância de recursos. Entre a primeira cavalgada no fim da madrugada e o fim de um dia de trabalho, já na escuridão da noite, tivemos uma chance de conhecer um pouco melhor um ao outro. No final do dia estávamos ambos cansados, e ele ainda tinha uma ovelha para carnear. Tendo como som de fundo o ritmo dos cortes da faca, Julio confidenciou-me que não gosta de trabalhar como peão, mas viu-se sem opções.

Julio estava para se casar. Ele conhecia a garota há seis meses. Ela era sobrinha do tosquiador de ovelhas com quem ele fez amizade quando este passou um tempo na estância como trabalhador temporário. No dia em que Julio me contou sobre sua noiva e sobre seu plano de casamento, estávamos sozinhos na estância. O patrão havia retornado para a cidade no fim do dia e o capataz ainda não havia voltado de suas férias. Tomamos mate no início da manhã e, após um rápido e simples café da manhã, encilhamos nossos cavalos e cavalgamos para checar as manadas e distribuir rações em alguns dos pastos cercados. Através da manhã, cavalgamos lentamente por sobre as leves ondulações da campanha, conversando. Além da questão do regime de trabalho na estância, Julio falou sobre sua vida até então. Disse que havia terminado a oitava série na escola rural local, em 1999, mas nunca chegou a se matricular no ensino médio (passo seguinte, caso tivesse continuado a estudar) porque este nível só estava disponível na sede do município e ele não possuía qualificações para obter um emprego na cidade. Sua classe na oitava série era composta por duas garotas e seis rapazes. Julio soube me dizer o que cada um de seus colegas havia feito após sair da escola. Uma das garotas continuou seus estudos na capital do estado, Porto Alegre, e tornou-se enfermeira, enquanto a outra, tornou-se professora. De seus colegas homens, quatro estão empregados em atividades agrícolas não qualificadas, na cidade de Dom Pedrito. Os outros dois, que eram irmãos, puderam freqüentar o segundo grau na cidade porque 
a mãe lhes pagou o aluguel. Mas, após um ano, eles voltaram à campanha e, mais tarde, migraram para Caxias do Sul, cidade situada na região mais industrializada do estado, em busca de trabalho. O próprio Julio considerou a possibilidade de migrar para Porto Alegre. Um tio, residente naquela cidade identificou um possível emprego para ele. Julio ainda leva em consideração tal possibilidade, mas na época da pesquisa, seu plano era viver na pequena propriedade de seus pais, onde tem uma casa simples, e uma área de terra havia sido cercada para ele.

No mesmo dia, terminada a maior parte das atividades da manhã de trabalho, tivemos tempo suficiente para cavalgar até o topo de uma elevação e observar a paisagem. Montados em nossos cavalos e com a estância inteira sob nossos olhos, nos entretemos com um quintessencial passatempo brasileiro: sonhar em ganhar na loteria. De acordo com Julio, se ganhasse na Mega Sena, compraria uma estância, mas também compraria uma boa casa na cidade, para descansar nos finais de semana. Comprar uma estância, povoá-la de gado e viver dela: essa era a sua idéia de uma "vida de sonhos". Ela sugere que sua vontade de abandonar a vida na campanha em favor de oportunidades de outra ordem em outros lugares não está baseada no desgosto da vida rural, mas em uma insatisfação com as condições de trabalho contemporâneas de um peão assalariado: o aumento na carga de trabalho, conflitos com patrões e capatazes, inflação não acompanhada por mudanças no salário.

Atualmente, o universo rural da Campanha gaúcha oferece uma vida dura e perigosa, em face da qual as compensações são vistas como insuficientes. As mudanças ocorridas no estilo de vida dos patrões têm sido acompanhadas de mudanças no modo como estes estabelecem relações com os peões, que ser afastam do modelo de patronagem que os peões esperam, e assumem cada vez mais práticas baseadas em um modelo de assalariamento. Mas as expectativas de compensação por parte dos peões vão além do salário.

\section{$O$ valor da vida gaúcha}

Além de definir um modo de vida específico, as habilidades que os peões descrevem como "campeirismos" são percebidas por eles em termos de noções sociais de valor. O termo gaúcho, para os peões, não é usado comumente como substantivo - "ser um gaúcho". Eles o usam como um adjetivo, no sentido de qualificar alguém como habilidoso nos campeirismos, atividades realizadas principalmente a cavalo e que definem um modo específico de interagir com o ambiente da campanha e seus elementos.

Frente à tendência dos estancieiros de promoverem uma lógica administrativa, racionalista e com ares modernizadores na organização do 
trabalho em suas estâncias, a escala de valores dos peões baseia-se numa lógica na qual a proficiência em certas habilidades ocupa um papel central. Ao invés de números e índices de produtividade, os peões, privilegiando certos tipos de tarefas, valorizam um determinado ritmo de trabalho e a possibilidade de executarem os serviços fazendo uso de suas habilidades. O exemplo mais marcante é o valor diferenciado atribuído às atividades em função delas serem realizadas a pé ou a cavalo.

É comum entre os peões a queixa de que o capataz está disposto apenas a dar ordens, sem envolver-se, ele próprio, em outro trabalho que não a doma de animais ou as atividades que envolvam laçar ou cavalgar. Essas tarefas são consideradas, tanto por peões quanto por capatazes, as mais prazerosas, nobres e adequadas a um gaúcho. São também estas as atividades que comumente se confundem com ou se sobrepõem ao lazer, além de aparecerem nos rodeios como demonstrações de habilidades que conferem status. Estas responsabilidades, e outras associadas a elas, ocupam uma posição elevada em termos dos valores compartilhados pelos peões. Qualquer trabalho levado a cabo a pé, tal como o reparo de cercas e o corte de madeira, é considerado inferior, tanto em termos de status, quanto do prazer que é capaz de proporcionar, sendo, na medida do possível, evitado.

Os rodeios são a celebração das habilidades gaúchas. Uma parte considerável dos competidores em rodeios são peões vindos de estâncias dos quatro cantos do município que sedia o evento. Durante a pesquisa de campo, muitas vezes reencontrei em rodeios peões que eu havia conhecido nas estâncias. Certa ocasião, eu acompanhava um estancieiro em sua visita a uma estância vizinha com o intuito de pegar emprestada uma serra de fita para cortar as partes de uma carcaça de boi que havíamos sacrificado no dia anterior, quando ele me apresentou a Onório, um peão com quem mantinha boas relações. Um pouco antes do encontro, em tom jocoso, o estancieiro havia me contado que Onório era um "falador". "Dá corda pra ele e só escuta", sugeriu-me o estancieiro. Onório ficou imediatamente interessado no fato de eu estar desenvolvendo um projeto de pesquisa e passou a exibir seu conhecimento, perguntando sempre: "o senhor sabe o que é isso?", o que era seguido, sem intervalo, de explicações sobre tudo o que ele julgava haver alguma chance de eu não conhecer, de modo que ele pudesse me surpreender com seu conhecimento de coisas incomuns para olhos urbanos, uma delas foi o uso da "vaca parada", artefato que eu conhecia mas sobre o uso do qual deixei que ele me explicasse. Trata-se de uma estrutura feita de madeira e outros materiais, compreendendo um corpo e uma cabeça, que os gaúchos usam para simular uma vaca quando treinam o uso do laço, desmontados. Crianças começam a laçar usando uma "vaca parada" 
como alvo, e os peões podem usá-la para aperfeiçoar sua proficiência com o laço, quando não estão nos campos.

O laço, assim como diversas outras atividades presentes nos rodeios, simula as atividades pastoris da campanha. Entre as diversas mudanças introduzidas pelos estancieiros, a diminuição no uso do laço como estratégia de manejo dos animais é uma das que desagradam aos peões. Muitas dessas mudanças têm a finalidade de reduzir custos, tornando o gado manejável por um número menor de peões ou diminuindo acidentes e mortes de animais. Mas, além disso, elas refletem os novos aspectos da escala de valores compartilhada pela, agora urbanizada, classe patronal. Por exemplo, o uso de currais para separar animais específicos das manadas é considerado por eles como uma técnica mais moderna e racional do que o uso do laço, e mais adequada a uma visão da atividade pecuária como negócio.

$\mathrm{O}$ alto valor atribuído pelos peões a atividades campeiras realizadas a cavalo indica que suas escolhas são influenciadas, tanto por condições econômicas - o que poderia sugerir adequabilidade a um modelo de agência racional -, quanto por uma escala de valores que nega tal possibilidade. Mesmo frente a condições de trabalho consideradas por eles mesmos como inadequadas, a atração por outros modos de vida, como o urbano, por empregos em outro tipo de atividade, não é suficiente para suplantar o desejo por uma vida na campanha, a cavalo, um tipo de vida a qual eles atribuem um grande valor. José, outro peão que conheci, confidenciou-me que já perdera empregos em diversas estâncias porque os patrões não gostavam de homens de rodeio. E mesmo a existência do brete nas estâncias não é considerada uma garantia, porque os peões dados a rodeios freqüentemente praticam laço em animais em disparada no final do dia.

Esta imposição dos patrões sobre os peões, que se baseia em uma lógica empresarial particular, interfere com os gostos e valores dos peões, já que a proficiência com o laço é considerada parte importante de seus campeirismos, técnicas e habilidades, é o parâmetro através do qual eles se comparam uns aos outros, e que usam como referência quando comparam seus conhecimentos, considerados superiores - com os de seus patrões.

As escalas de valores compartilhadas por peões e patrões - abordados como grupos sociais - são dinâmicas e, muitas, vezes excludentes. As ideologias modernizadoras disseminadas entre os estancieiros da Campanha gaúcha têm reduzido o espaço para as habilidades campeiras dos peões em seu contexto laboral, habilidades estas que são vistas como centrais na definição do modo de vida e na experiência de estar-no-mundo dos peões gaúchos, fundamentais, portanto, na definição da identidade dos mesmos. 
A escala de valores dos peões pode colocar em conflito as suas oportunidades de emprego com o esforço dos trabalhadores em maximizar sua reputação nos rodeio. Outro valor importante é a liberdade, mas um certo tipo de liberdade, aquela que se opõe à proletarização. Este valor transparecerá mais claramente na próxima seção, em que se discute sobre as noções de resistência, sobre os desejos e os projetos que transparecem nas narrativas dos peões.

\section{Dominação e resistência}

Durante o final dos anos 1980 e a primeira metade dos 1990, diversos artigos publicados identificavam atos de resistência e/ou acomodação em contextos extremamente distintos. Em seu livro seminal, Domination and the arts of resistance, Scott sugere que, através do conceito de "registro oculto", "nós podemos ler, interpretar e compreender com maior sucesso as frequentemente fugidias condutas políticas de grupos subordinados" (Scott, 1990, p. 17). Embora ele não pretendesse que essa abordagem apresentasse a resolução de todos os problemas teóricos e metodológicos envolvendo os conceitos de dominação e de resistência, o caráter ambicioso de seu objetivo atraiu críticas severas ${ }^{3}$. Se alguns declararam que o conceito de resistência tinha morrido ou deveria morrer (Sahlins, 2002; Brown, 1996), outros se dedicaram a avançar na discussão, buscando refinar o conceito e seus usos.

Ortner (1995) sugeriu a busca por maior densidade etnográfica como uma cura para a fraqueza com que o conceito vinha sendo aplicado, e Gledhill (2007) afirmou que o conceito de resistência, devidamente reformulado à luz de novas pesquisas e de uma percepção mais ampla sobre o tema do poder, apenas começara a oferecer sua contribuição à compreensão das relações de poder. Assim, embora o uso do conceito de resistência possa ter sido abusivo, penso que ele é capaz de abrir os olhos do observador antropológico a nuances previamente ocultas. Mas isto só pode acontecer se o conceito for usado como ponto de partida, abrindo caminho em direção a maior complexidade (Bornholdt, 2008).

Para se evitar a armadilha de reificar o político, a solução é buscar a identificação e análise de fenômenos que não são exclusivamente políticos nem exclusivamente apolíticos, e seguir a sugestão de Ortner (1995), de que

\footnotetext{
2 "Todo grupo subordinado cria, a partir de sua dificuldade, um 'registro oculto' que representa uma crítica ao poder, falada às costas daquele que domina" (Scott, 1990, p.17) (traduções do autor). O registro oculto inclui, além do discurso, os atos dos subordinados, e é, na abordagem de Scott sobre o poder, a origem dos atos e discursos de resistência.

3 Para uma revisão do debate, veja Gledhill (2007) e Bornholdt (2008).
} 
a resistência - e a acomodação - de sujeitos submetidos a uma relação de dominação pode ser identificada nas subjetividades dos mesmos: seus desejos, intenções, medos e projetos. Onde há poder e sujeitos, há ambigüidades nos projetos das pessoas, afirma a autora (Ortner, 1995). Assim, os atos e narrativas de resistência dos peões em relação aos atos de seus patrões servem tanto para aumentar nossa compreensão da dimensão de poder imbuída nessa relação, quanto para nos permitir acessar os valores culturais através dos quais os sujeitos fazem suas escolhas e julgam suas opções, como vimos na seção anterior.

A estratégia dos proprietários para manterem a atividade pecuária viável - o que também significa resguardar o mehor possível a posição social e econômica de suas famílias - é cortar custos de operação de suas estâncias, através da intensificação da exploração da força de trabalho, já que, diminuindo o número de peões, os restantes precisam trabalhar mais para obter os mesmos resultados.

A soma de certas mudanças tecnológicas tais como o uso de cercas de arame farpado e elétricas, rotação de pastos, complementação do pasto com ração e uso de remédios que permitem aplicações menos freqüentes, permite que os estancieiros utilizem um menor número de peões para trabalhar em suas estâncias. Entretanto, a razão pela qual eles tiram proveito dessa possibilidade pode ser encontrada em seus projetos. Reduzir o número de trabalhadores é, de fato, uma resposta a pressões econômicas de escopo nacional e internacional, visando proteção de uma parte de seu estilo de vida. Trata-se, também, de uma opção, no sentido de que eles escolhem entre o lucro e o controle sobre outros homens. Eles protegem seu poder de consumo mas perdem o tipo de poder que seus pais detinham sobre um número maior de peões. Seus projetos, frente a um mundo em transformação, mostram que o desejo por um certo modo de vida urbano e moderno suplanta o desejo do poder político.

A dominação do patrão sobre seus peões se manifesta fortemente em seus corpos, através do controle parcial que o estancieiro é capaz de exercer sobre o ritmo de trabalho em sua estância. Na perspectiva inversa, uma das formas de dominação sentidas com particular força e imediatez pelos peões diz respeito à dinâmica do trabalho que lhes é imposta, exigindo um ritmo muito mais acelerado do que o que eles próprios escolheriam, na perspectiva de seu conhecimento e habilidade.

Durante uma entrevista, Renato, um jovem estancieiro, afirmou que "a estância precisa ser um negócio, tem que ser lucrativa, antes de tudo." Estancieiros frequentemente afirmam que "a vida não está fácil" também para eles, e não apenas para os peões. De acordo com os próprios estancieiros, viver 
na cidade demanda bens tais como automóveis, telefones celulares e roupas, que os obrigam a gastos que seus pais não tinham, pois viviam nas estâncias. De acordo com um deles, "antes eu trabalhava com cinco peões e mais um cozinheiro; hoje meu filho trabalha só com três e funciona tudo do mesmo jeito". Poucos meses depois, ao visitar a mesma estância, encontrei apenas dois peões dando conta da mesma carga de trabalho. Para esses peões, certamente, não funciona tudo do mesmo jeito. Pelo contrário, queixas relativas ao ritmo de trabalho extenuante imposto pelos patrões - na maior parte do tempo utilizando o capataz como instrumento de controle - são comuns na campanha. Comuns também são algumas táticas de resistência dos peões, buscando fugir do controle e dos olhos do patrão: o ritmo de trabalho é bem mais lento quando o patrão não está na estância, e é ainda mais calmo quando o capataz se encontra ausente; avaliações negativas acerca das habilidades eqüestres do patrão como forma de expor sua insuficiência abundam, assim como as críticas às suas decisões administrativas, mas apenas quando este não se encontra presente.

Para além dessas táticas de resistência, os peões buscam envolver seus patrões em negociações que visam melhorar suas condições de trabalho e criarlhes oportunidades. Essas negociações são apoiadas por narrativas tecidas a partir do universo cultural dos peões, que citam exemplos do passado ou de outras estâncias em que o patrão permitia aos peões o acúmulo de uma pequena tropa de animais. A permissão para criar animais próprios na estância em que trabalham é uma das principais formas de ascensão social disponível aos peões em seu universo cultural e econômico. Com a possibilidade de capitalização apresentada pelo acúmulo de uma tropa de gado e cavalos, o peão tem a chance de fazer o primeiro pagamento de um pequeno rancho próprio. Isso pode representar a saída da vida assalariada na qual ele é diretamente dependente de seu patrão, em direção a um grau maior de liberdade.

Peões, em geral, e, especialmente, os capatazes esperam de seus patrões mais do que apenas o salário, pois afirmam dar-lhes mais do que o seu trabalho. Eles dizem que, através de seu conhecimento, do cuidado que dispensam aos animais, de seu cuidado com a estância de seus patrões, eles lhes dão a riqueza que possuem. Numa tarde, enquanto checávamos os campos a cavalo, o capataz da estância Santa Rita me confidenciou que gostaria de receber mais ajuda de seu patrão porque lhe havia dado muita riqueza nos seis anos em que foi responsável por sua estância. Essa ajuda poderia ser em forma de auxílio na compra de uma casa na cidade ou de permissão para que ele criasse animais próprios na estância. Como muitos outros peões e capatazes, Valdir considera seu trabalho atual sacrificado e acredita que seu patrão pressiona os 
peões para extrair deles a maior quantidade possível de trabalho, sem jamais lhes dar algo em troca.

O salário não é visto, portanto, como retribuição suficiente. Quando eles falam em receber algo em troca de tudo o que fazem e oferecem, os peões se referem a "uma chance" ou a "uma ajuda" que os auxilie a mudar a sua situação econômica e social. Embora estas falas aparentemente reivindiquem reciprocidade na relação patrão-peão, reciprocidade essa informada por um passado imaginado como igualitário e em oposição à lógica moderna de trabalho assalariado, as lógicas envolvidas na construção das narrativas dos peões vão além da idéia de "tradição" versus "modernidade". Elas vão em direção à resistência à dominação social e econômica, através da criação de significados que extrapolam o âmbito de um relacionamento clientelista. Através das narrativas, peões resistem aos projetos de seus patrões, buscando controlar os termos da relação. Essas narrativas introduzem outras interpretações da relação e outras lógicas na percepção e avaliação de seu trabalho.

\section{Conclusão}

Assim como os criadores de gado respondem às mudanças tentando adaptar-se dinamicamente ao contexto que os ameaça, os peões também têm sabido responder às mudanças que enfrentam.

Conforme já foi argumentado, patrões e peões não respondem às mudanças no seu ambiente ${ }^{4}$ a partir de uma suposta razão universal, mas a partir de sua própria escala de valores. Além disso, eles estão envolvidos numa relação hierárquica desigual. Assim, muitas das estratégias empregadas pelos estancieiros para garantir a própria posição econômica e social, como o uso de novas técnicas pecuárias (que lhes permitem contratar um número menor de peões), implicam restrições aos peões.

A combinação das particularidades da relação entre peões e patrões se expressa na resistência dos peões aos projetos de dominação de seus patrões. A maioria dos atos de resistência levados a cabo por eles se orienta por uma lógica compensatória e são levados a cabo em uma escala individual, e não através de protestos organizados (Giddens, 1982). Por isso, é impossível compreendê-los sem entender as subjetividades dos atores. O peão gaúcho ainda tenta fugir da proletarização através da independência econômica.

4 Entendo ambiente aqui do modo mais amplo, focando nas relações ao invés dos elemntos, numa perspectiva inspirada em Ingold (2000) e desenvolvida para o presente caso em Bornholdt (2008). Na categoria ambiente incluo, além dos elementos naturais das pastagens ocupadas por gado, cavalos e outros animais, as relações dos peões com seus patrões, com capatazes e outros peões, assim como os efeitos de mudanças macroestruturais que envolvem os indivíduos. 
Os desejos de ambas as classes de atores enfrentam limites concretos. A principal diferença entre elas é a posição social e econômica dos estancieiros e de suas famílias, que lhes oferece uma maior margem de manobra, se comparadas à posição dos peões. Além da atividade pecuária, os filhos de estancieiros têm à sua disposição recursos financeiros suficientes para permitir seu ingresso em uma profissão liberal. As vias de reprodução social e manutenção de sua posição de dominação na economia regional, embora diminuída em tempos mais recentes, ainda é claramente maior do que as possibilidades de ascensão social dos peões. O que torna o universo de oportunidades díspares entre um e outro é o fato de que a maioria das vias de ascensão social disponíveis aos peões depende direta ou indiretamente de seus patrões.

Peões dos ranchos latino-americanos apenas raramente conseguem acumular recursos suficientes para comprar terra e tornarem-se eles próprios criadores de gado. Slatta (1994) sugere que o monopólio do acesso à terra por parte das elites proprietárias teve um papel central nesse contexto, tanto no passado quanto na contemporaneidade da América Latina. Historicamente, a fronteira rio-grandense, rica em gado selvagem, garantiu ao gaúcho alguma liberdade, mas certamente não ofereceu oportunidades. Como na Argentina, os grandes proprietários que compunham a elite pecuarista do Rio Grande do Sul foram capazes de garantir vantagens para si próprios, impondo sua posse sobre a terra e exercendo controle sobre a população rural, majoritariamente pobre.

A ascensão social e econômica para o gaúcho se manteve improvável e difícil devido às leis que protegiam os interesses da elite proprietária de terra, associadas aos baixos salários, possíveis devido ao eficaz controle sobre a população que compunha a força de trabalho regional. A probabilidade de uma vida relativamente livre de dominação desapareceu junto com o fim da fronteira aberta e do gado sem dono. A escassez de oportunidades foi uma característica comum a todas as fronteiras ricas em gado das Américas.

O gaúcho contemporâneo enfrenta problemas similares. O contexto não é mais de fronteira aberta e, embora haja alguns pequenos ranchos na campanha, o gaúcho é, na maior parte dos casos, um peão que trabalha nas estâncias da elite proprietária de terra. Isto se não migrou para a cidade mais próxima ou além, cansado da falta de oportunidades e fatigado pela vida de trabalho duro nas estâncias. Seu relacionamento com o patrão modificou-se e adaptou-se para abrir espaço a novos atores e novos contextos, assim como para novos projetos e estratégias de ambas as partes.

Embora patrões e peões compartilhem certas características em termos de comportamento e práticas econômicas, são guiados por valores distintos e têm opções irremediavelmente diferentes. A elite e os peões gaúchos estão em 
extremos opostos de uma relação de dominação social e econômica. Enquanto as estratégias de reprodução da posição social das famílias dos estancieiros são relativamente variadas, os peões enfrentam elevadas dificuldades. A combinação desses fatores garante a continuidade de relações hierárquicas desiguais, mesmo que os peões gaúchos - muito longe de serem vítimas passivas - resistam e negociem os termos dessa relação.

\section{Referências}

BORNHOLDT, L.C. Gaúchos and estancieiros: regionalism, work relations and identity in the Campanha gaúcha, southern Brazil. PhD. University of Manchester/ UK, 2008.

BROWN, M. F. On resisting resistance. American anthropologist, New Series, 98(4), p. 729-735, 1996.

GIDDENS, A. Class structuration and class consciousness. In: GIDDENS, A.; HELD, D. (Org.). Classes, power and conflict: classical and contemporary debates. London: Palgrave Macmillan, 1982. p. 157-174.

GLEDHILL, J. Recognizing resistance. 2007. Disponível em: <http://www.llc. manchester.ac.uk/clacs/research/projects/RethinkingHistoriesofResistance/Seminarin Brazil/-d.en.122077>. Acesso em: 10 ago. 2010, 16:40:30.

INGOLD, T. The perception of the environment: essays on livelihood, dwelling and skill. London: Routledge, 2000.

KÜHN, F. Breve história do Rio Grande do Sul. Porto Alegre: Leitura XXI, 2004.

ORTNER, S. B. Resistance and the problem of ethnographic refusal. Comparative studies in society and history, v. 37, n. 1, p. 173-193, 1995.

PESAVENTO, S. J. História do Rio Grande do Sul. Porto Alegre: Mercado Aberto, 2002.

SAHLINS, M. Waiting for Foucault, still. Chicago: Prickly Paradigm Press, 2002. Disponível em: <http://www.prickly-paradigm.com/catalog.html>. Acesso em: 10 ago. 2010, 16:42:30

SCOTT, J.C. Domination and the arts of resistance: hidden transcripts. Yale University Press, 1990.

SLATTA, R. W. Cowboys of the Americas. Yale: Yale University Press, 1994.

SLATTA, R. W. Gauchos and the vanishing frontier. Lincoln and London: University of Nebraska Press, 1983. 